\title{
HEALTH POLICY \\ Physicians Asking Patients About Guns: Promoting Patient Safety, Respecting Patient Rights
}

\author{
Brendan Parent, JD
}

Applied Bioethics Program, NYU School of Professional Studies, New York, NY, USA.

Recent debate on whether physicians should discuss gun ownership with their patients has centered on determining whether gun injuries are an issue of health or safety, and on protecting patient privacy. Yet, physicians' duties span personal health, public health, and safety spheres, and they often must address private patient matters. To prioritize gun safety and reduce gun injuries, the primary policy-driving question should be: will physician counseling on gun ownership effectively reduce gun-related injuries without interfering with the physician's other treatment obligations or compromising the physician-patient relationship? Existing data on physician-initiated conversations with patients about guns support a positive prevention effect. However, it is critical that physicianinitiated discussions of safe gun practices are not motivated by, nor convey, disapproval of gun ownership. To be ethical, respectful, and efficient, the conversation should be standard between primary care providers and all of their patients (not limited to patient subsets); questions and education should be limited to topics of gunownership risks and storage practices; and the conversation must be framed without bias against gun ownership.

KEY WORDS: public health; health policy; preventive care; guns; patient safety.

J Gen Intern Med 31(10): 1242-5

DOI: $10.1007 / \mathrm{s} 11606-016-3694-2$

(C) Society of General Internal Medicine 2016

\section{TEXT}

In 2011, Florida became the first state to pass a law prohibiting physicians from asking whether their patients own guns. ${ }^{1}$ Twelve other states have since introduced similar legislation. These laws are based on the misdirected beliefs that gun safety is not the physician's responsibility, ${ }^{2,3}$ that doctors discussing guns in the clinical setting violates patient privacy, ${ }^{4}$ and that physicians are unable to separate personal feelings about guns from their professional duties. ${ }^{5}$ For the reasons outlined here, physicians are not only well-positioned to promote patient safety with regard to firearms, but have a responsibility to do so while respecting patient rights. The comfort some gun owners might find in legal sanctions against physician-

Received October 16, 2015

Revised March 4, 2016

Accepted March 25, 2016

Published online May 20, 2016 initiated gun conversations does not justify the loss of effective and respectful life-saving interventions.

In the United States over the past three decades, there have been approximately 33,000 gun-related fatalities and 80,000 nonfatal gun wounds per year. 6,7 The cumulative economic cost for gun victims in 2010 was estimated at 174.1 billion-more than the US government paid during the same year to operate the Department of Education, Department of Energy, and NASA combined. ${ }^{7}$ Our healthcare system spends a great deal treating gun wounds, leading many to refer to the issue as a public health crisis. ${ }^{8}$ Physicians must discuss gun ownership with their patients to reduce these societal burdens.

Some argue that gun-injury prevention through patient counseling is not the physician's responsibility in the clinical setting. ${ }^{9}$ However, all physicians work to reduce harm to their patients. Unfortunately, most gun injury fatalities occur within $24 \mathrm{~h}$ of being shot, and few who survive fully recover. ${ }^{8}$ These facts make it difficult for physicians to reduce harm from gun injuries through treatment alone. If modifying patient gunownership behavior can reduce the infliction of gun injuries, then the best form of treatment is prevention.

Data already exist to support positive effects of physicianinitiated gun conversations. One study found that 25-31\% of subjects improved gun storage practices after physician counseling; another showed that $81 \%$ of African American patients believe physicians should discuss guns with them; another in a predominantly Hispanic pediatric clinic demonstrated $61.6 \%$ improvement in storage practices after counseling. ${ }^{10}$ The conversations are happening, and based on limited data, appear to be working.

Some opponents of the physician-patient gun conversation believe that people with mental illness are the primary source of gun injuries. Although nearly 600 lives have been claimed in mass shootings in the past 32 years, several tied to mental illness, gun violence has killed more than a quarter million people over the past decade. ${ }^{6}$ The best national data suggest that only 3-5\% of violent acts involve mental illness, and most of those acts do not involve guns. ${ }^{11}$ Mental illness does account for a substantial number of gun-related suicides, and suicide accounts for a significant number of annual gun deaths. ${ }^{6}$ However, firearm availability in the home is the most significant risk factor for suicide, regardless of mental illness. ${ }^{12,13}$ Because guns are rarely purchased for the purpose of suicide, ${ }^{14}$ interventions need to address guns that are already in the home. Physician discussions about depression and 
rage, which incorporate lethal weapon education, have been shown to decrease suicide rates and future violence. ${ }^{15,16}$

Several laws, including the Brady Act and its amendments, have been implemented to increase background scrutiny and increase gun-purchase waiting period, yet studies have shown that national gun injury and fatality rates have not decreased after their implementation. ${ }^{11}$ Furthermore, around $40 \%$ of gun sales are by private owners and are unaffected by such laws. ${ }^{11}$ Background checks and waiting periods should be supplemented by physician counseling.

Opponents also argue that the doctor's domain is limited to "health" issues, and "public safety" issues are off-limits. ${ }^{2,3}$ If true, this would preclude physicians from addressing risks originating in the external environment. For years, pediatrician conversations about car seats have boosted their use, ${ }^{17}$ which has led to significant reduction in infant car injuries and fatalities. ${ }^{18}$ Physician-initiated safety discussions to prevent vehicle injury, improve diet, and reduce drug use have become commonplace. ${ }^{19}$ So what, if anything, characterizes the prevention of gun injuries as beyond the physician's concern?

One argument is that organizations like the National Rifle Association and local gun clubs exist to provide effective gunsafety training. However, safety training is only required for ownership in six states and there is no federal requirement. ${ }^{20}$ There does not appear to be data on the number of gun owners who seek training, and research shows that safety information is rarely provided at the time of gun purchase. ${ }^{21}$ With 270 million guns in one-third of U.S. households, ${ }^{11,22}$ and many of those unregistered and/or purchased privately, ${ }^{11}$ it is unlikely that safety instruction reaches most gun owners. In contrast, over $82 \%$ of adults and over $92 \%$ of children in the US had contact with a healthcare professional in 2012, and $55.5 \%$ of visits were to primary care physicians. ${ }^{23}$ Physician-initiated gun conversations can reach individuals who do not receive training or safety information elsewhere.

Many believe that physician-initiated gun conversations violate patient privacy. ${ }^{4}$ However, patients are not required to engage in gun discussions, and they should not incur repercussions for refusing to answer related questions. If a physician refuses to treat a patient on these grounds, then the patient deserves to find another physician less blinded by personal beliefs. Some patients may feel coerced to answer their physicians' questions due to power dynamics, which would reinforce the need to empower patients in healthcare settings, but questions about gun ownership do not uncharacteristically pry into patients' personal lives. Gun ownership is not more personal than sexual practices, smoking habits, or vaccine status, all expected medical topics. It is accepted that physicians will seek relevant private patient information to provide effective care. Gun ownership is relevant because of its significant correlation with physical injury.

Despite this, Florida's "doctor gag order" law passed in 2011 (currently under appeal), ${ }^{1}$ and twelve other states are working on similar laws. The validity of such laws hinges in part on whether medical care is protected as free speech under the Constitution. The latest court interpretation requires a "reasonable fit" between a prescribed restriction on professional-client speech and the important reason justifying the restriction, in this case characterized as the protection of patient privacy. ${ }^{24}$ Gun ownership is not a more private subject than other accepted medical topics, including sexual practices and smoking behavior. Nor are patients required to respond to physicians' gun questions, so the patient's personal sphere is not infiltrated without permission.

Parts of the gun lobby support gag laws because they believe that physicians intend to share information about gun owners with government to create tracking databases. ${ }^{25} \mathrm{~Pa}$ tient medical records are subject to strong privacy laws governed by the Health Insurance Portability and Accountability Act. If such private data transfer occurred, physicians would be subject to severe penalties including major fines, prison time, and revocation of licensure. ${ }^{26-28}$ Physicians know that consequences are not limited to their individual practices - the field of medicine is jeopardized by breaches of patient trust. Gun ownership discussions are, and will always be, held in the same confidences as all physicianpatient conversations.

Due to the quantity and severity of gun injuries, many physicians are against keeping guns in the home. Regardless of what proportion they constitute of the total physician population, we must trust in each physician's ability to separate personal views from professional care. If we limited physicians' rights to discuss other private topics to prevent the possibility that their beliefs would inform their delivery of care, then fewer children would be vaccinated, more would be injured in car accidents, sexually transmitted infections would be more rampant, and more people would die of drug-related diseases. Physician intervention in these realms has been critical to successful treatment and containment of serious public health problems. It is important, however, that the physician's responsibility to discuss gun ownership, as well as these other topics, be carried out so as to preserve confidentiality and prioritize neutrality.

One final argument against physician-initiated gun conversations is that physicians have limited time. The average visit in a primary care provider's office lasts somewhere between 10 and 18 min. ${ }^{29}$ During that time, the physician must address the patient's primary concern and evaluate other health risks. For health/safety risks without symptoms or previous record, relevant patient information should be collected. However, the potential list of risks is infinite. How does a physician decide whether to ask about jaywalking, texting while going down stairs, smoking, owning a pool, wearing a helmet while riding a bicycle, cutting vegetables while watching TV, or owning a gun?

Examined risks should be based on the severity and likelihood of associated injuries. Data may not exist yet on injuries from texting while walking, but enough data exists on gun injuries such that reputed medical associations classify them as a public health crisis. ${ }^{30}$ It may well be that owning a pool puts 
a child at greater statistical risk for injury than her parents owning a gun, ${ }^{31}$ in which case a question about pool ownership should be asked of parents. There should be an objective threshold for determining what topics are worthy of the primary care provider's limited time with her patients. The annual 33,000 deaths and 80,000 injuries caused by guns put enough people at risk to qualify the subject of firearms among physician counseling duties.

\section{RECOMMENDATIONS}

If the discussion were to jeopardize the patient's trust in the physician, then both the goal of reducing gun injuries as well as the physician's ability to provide effective health care would be impeded. It is important for primary care physicians to broach the topic with all patients, and to do so in a uniform manner least likely to create offense. Accordingly, the following recommendations have been crafted to promote neutrality, privacy, and respect:

\section{Prohibit Discrimination on the Basis of Gun Ownership}

This recommendation is codified generally in the Hippocratic Oath, ${ }^{32}$ and enshrined in the codes of the American Medical Association and the American College of Physicians. ${ }^{33}$ In practice, it means not changing or refusing care to patients who do not engage in gun conversations, or to those who acknowledge gun ownership.

\section{Limit Question Being Asked, and Information Provided}

Physicians should first remind patients that all information collected will remain completely confidential. Then, the question should be along these lines: "Are guns kept in the household?" Objective phrasing is less likely to be misinterpreted as judgment laden. If the patient refuses to answer, then the physician can indicate availability of gun safety information, but then the subject should be over.

If the answer is affirmative, the physician should acknowledge that the patient might already know the information about to be provided, and that it is given to all patients who have guns in the home, and to those interested. Physicians should frame objective information "empathetically, without explicit orders to do something," as Drs. Betz and Wintemute suggest. ${ }^{34}$ The most relevant physician intervention is education on gun risks and injuries, especially those in the home and between whom they occur. The physician should also explain the safety benefits of keeping firearms stored in locked safes or storage cases when not in use, disarming them with gun locks while not in use, and keeping ammunition stored in a separate locked safe or storage case. ${ }^{35}$ These facts stand on their own logic and do not require special training to offer with authority.

\section{Seek Support}

Information on storage, risk, safety, and local training can be provided verbally or in written form. Relevant pamphlets and talking points are freely available from a variety of organizations, including Project Child Safe ${ }^{35}$ and the American Academy of Pediatrics. ${ }^{36}$ Betz and Wintemute also suggest that physicians who do not own guns could seek cultural competence counseling from the 13-41\% of physicians who do own guns. Dr. Betz even has a TedX talk on "How to Talk to Patients about Guns and Suicide," which is available on YouTube. ${ }^{37}$ While physician concern about how best to approach the topic is justified, available resources allow all physicians to be up to the necessary task.

Acknowledgements:

Contributors: The author would like to thank Art Caplan for constructive feedback.

Funders: No financial support was provided for the creation of this article.

Prior Presentations: This work has not been presented in any form.

Corresponding Author: Brendan Parent, JD; Applied Bioethics ProgramNYU School of Professional Studies, 7 E. 12th St, Ste 825, New York, NY 10003, USA (e-mail: brendan.parent@nyu.edu).

\section{Compliance with Ethical Standards:}

Conflict of Interest: The author declares that he does not have a conflict of interest.

Contributorship: Brendan Parent is responsible for all ideas and content in this article.

\section{REFERENCES}

1. Everytown for Gun Safety. Doctor Gag Order Laws. July 9 2015. Last accessed March 24, 2016. http://everytownresearch.org/fact-sheet-doctor-gag-order-laws/ (referencing Wollschlaeger v. Governor of Fla. [2015] U.S. App. LEXIS 13070)

2. Drum K. Should Doctors Ask You About Your Guns? Mother Jones. July 29 2014. Last accessed March 24, 2016. http://www.motherjones. com/kevin-drum/2014/07/should-doctors-ask-you-about-your-guns. (“...should physicians ask about gun ownership? I'm not so sure. [Dr.] Carroll says he only wants to discuss "health risks," and that's appropriate. Doctors have expertise in the area of human health: that is, the biology and physiology of the human body. But that's not the same thing as the safety of the human body.")

3. Physician Responses. Docs Should Promote Gun Safety With Patients: Caplan. WebMD, 2016. Last Accessed March 24, 2016. http://www. medscape.com/viewarticle/822576. (Physician and medical student responses to Arthur L. Caplan's video proposing that physicians should promote gun safety with patients include statements like: "Gun safety is not a public health issue. It is a public safety issue. As such it is not the doctors responsibility," and "We are health care professionals to our patients. We are not their mother. And this extension of "public safety" has nothing to do with our roles as such."

4. Physician Responses. Docs Should Promote Gun Safety With Patients: Caplan. WebMD 2016. Last Accessed March 24, 2016. http://www. medscape.com/viewarticle/822576. (Physician and medical student 
responses to Arthur L. Caplan's video explain that such counseling intrudes on patient privacy: "Citizens resent this intrusion into their privacy;" "This is interference with a patients privacy and with the patient's 2nd Amendment rights;" "A MD steps across the line of privacy when he requests information about firearms from his patients.")

5. Wheeler T. The Surgeon General's Gun Problem. National Review. January 7 2015. Last accessed March 24, 2016. http://www.nationalreview.com/ article/395842/surgeon-generals-gun-problem-timothy-wheeler.

6. Gold L. Gun violence: psychiatry, risk assessment, and social policy. J Am Acad Psychiatry Law. 2013;41(3):337-43

7. Lee J, Quraishi SA, Bhatnagar S, Zafonte RD, Masiakos PT. The economic cost of firearm-related injuries in the United States from 2006 to 2010. Surgery. $2014 ; 155(5): 894-8$.

8. Frattaroli S, Webster DW, Wintemute GJ. Implementing a public health approach to gun violence prevention: the importance of physician engagement. Ann Intern Med. 2013;158(9):697-8.

9. Young $\mathbf{R}$. Presentation supporting the Florida firearms owners privacy act Presented at AMA Litigation Center Open Meeting. Nov 9, 2014. Last accessed March 24, 2016. https://drgo.us/?p=575 (Young explains that "even being a psychiatrist, I rarely need to inquire about weapons. We can still promote our beliefs about firearms or anything else, like every other American, by speaking out or writing, making videos or mounting a soapbox-even by joining a forum like this.")

10. Butkus R, Doherty R, Daniel H. Reducing firearm-related injuries and deaths in the United States: executive summary of a policy position paper from the American college of physicians. Ann Intern Med. 2014;160(12):858-79.

11. Appelbaum PS, Swanson JW. Gun laws and mental illness: how sensible are the current restrictions? Psychiatr Serv. 2010;61(7):652-4.

12. Brent DA, Perper JA, Moritz G, Baugher M, Schweers J, Roth C. Firearms and adolescent suicide: a community case-control study. AMA AM J Dis Child. 1993;147(10):1066-71.

13. Brent DA, Perper JA, Allman CJ, Moritz GM, Wartella ME, Zelenak JP. The presence and accessibility of firearms in the homes of adolescent suicides: a case-control study. JAMA. 1991;266(21):2989-95.

14. Kellermann AL, Rivara FP, Somes G, Reay DT, Francisco J, Banton JG, Prodzinski J, Fligner C, Hackman BB. Suicide in the home in relation to gun ownership. NEJM. 1992;327(7):467-72.

15. Mann JJ, Alan A, Bertolote J, et al. Suicide prevention strategies: a systematic review. JAMA. 2005;294(16):2064-74

16. Umhau JC, Trandem K, Shah M, George DT. The physician's unique role in preventing violence: a neglected opportunity? BMC Med. 2012;10(1):146-53.

17. Bass JL, Christoffel KK, Widome M, Boyle W, Scheidt P, Stanwick R, Roberts K. Childhood injury prevention counseling in primary care settings: a critical review of the literature. Pediatrics. 1993;92(4):544-50.

18. Centers for Disease Control and Prevention, USA. MMWR Morb. Mortal. Wkly. Rep. 1991;40(34):600-602.

19. Galuska DA, Fulton JE, Powell KE, Burgeson CR, Pratt M, Elster A Griesemer BA. Pediatrician counseling about preventive health topics: results from the Physicians' Practices Survey, 1998-1999. Pediatrics. 2002; 109(5): $1-6$.

20. National Physicians Alliance, Law Center to Prevent Gun Violence. Gun Safety \& Public Health: Policy Recommendations for a More Secure America. 2013:1-20. Last accessed March 24, 2016. http://npalliance. org/blog/2013/09/25/doctors-and-lawyers-recommend-public-health policies-for-a-more-secure-america-2/.

21. Sanguino SM, Dowd MD, McEnaney SA, Knapp J, Tanz RR. Handgun safety: what do consumers learn from gun dealers? Arch Pediatr Adolesc Med. 2002; 156(8):777-80.
22. United States Census Bureau. USA, Households, 2009-2013. Last accessed March 24, 2016. http://quickfacts.census.gov/qfd/states/ 00000.html.

23. Centers for Disease Control and Prevention. Ambulatory Care Use and Physician Office Visits. 2012. Last accessed March 24, 2016. http://www. cdc.gov/nchs/fastats/physician-visits.htm.

24. Volokh E. Court upholds Florida law restricting doctor-patient speech about guns. The Washington Post. July 29 2015. Last accessed March 24 , 2016. https://www.washingtonpost.com/news/volokh-conspiracy/wp/ 2015/07/29/court-upholds-restriction-on-doctor-patient-speech-aboutguns/.

25. Rathore M. Physician "Gag laws" and gun safety. AMA J Ethics. 2014;16(4):284-8

26. 42 U.S.C. § $1320 d-5$.

27. United States Department of Justice. Scope of Criminal Enforcement Under 42 U.S.C. § 1320d-6. June 5 2005. Last accessed March 24, 2016. https://www.justice.gov/olc/opinion/scope-criminal-enforcement-under42-usc-1320d-6

28. NY C.L.S. Educ § 6530(9)(a). Being convicted of a state or federa crime can lead to loss of New York medical license under NY CLS Pub Health § 230-a. Most states, if not all, have similar provisions under which a conviction for a HIPAA violation would be grounds for loss of medical license.

29. Tai-Seale $\mathbf{M}, \mathbf{M c G u i r e}$ TG, Zhang $\mathbf{W}$. Time allocation in primary care office visits. Health Serv Res. 2007;42(5):1871-94. doi:10.1111/j.1475-6773. 2006.00689.x.

30. Weinberger SE, Hoyt DB, et al. Firearm-related injury and death in the United States: a call to action from 8 health professional organizations and the american bar association. Ann Intern Med. 2015;162(7):513-7.

31. Hsieh P. Why doctors should not ask patients about guns. Forbes. Jan 2013. Last accessed March 24, 2016. http://www.forbes.com/sites/ paulhsieh/2013/01/22/why-doctors-should-not-ask-their-patientsabout-guns/.

32. Association of American Physicians and Surgeons. A Modern Hippocratic Oath by Dr. Louis Lasagna. Last accessed March 24, 2016. http://www.aapsonline.org/ethics/oaths.htm. ("I will apply, for the benefit of the sick, all measures which are required...I will prevent disease whenever I can, for prevention is preferable to cure...I will remember that I remain a member of society, with special obligations to all my fellow human beings, those sound of mind and body as well as the infirm.")

33. Hood VL. Can a physician refuse to help a patient? American perspective. Pol Arch Med Wewn. 2008;118(6):368-71. AMA: physicians may not decline to treat patients on any "basis that would constitute invidious discrimination." ACP: "denial of appropriate care to patients for any reason is unethical."

34. Boggs W. Physicians Should Prepare to Counsel Patients on Firearm Safety. Healthy Living Magazine. Last accessed March 24, 2016. www. healthylivingmagazine.us/Articles/12173/.

35. Project Child Safe. Ten Tips for Firearm Safety. 2015. Last accessed March 24, 2016. www.projectchildsafe.org/news/ten-tips-firearm-safetyyour-home.

36. American Academy of Pediatrics. How Pediatricians Can Advocate for Children's Safety in Their Communities. Last accessed March 24, 2016. https://www.aap.org/en-us/my-aap/advocacy/workingwiththemedia/ speaking-tips/Pages/Firearm-Related-Injuries-Affecting-the-Pediatric-Population-Speaking-Points.aspx

37. Betz ME. How to Talk to Patients about Guns and Suicide. Presentation at TedX. Last accessed March 24, 2016. http://www.tedxmilehigh.com/ speakers/emmy-betz/. 